\title{
Cost of Illness in Young Children: A Prospective Birth Cohort Study
}

\author{
Sarah Kristine Nørgaard, Nadja Hawwa Vissing, Bo Lund Chawes (D), Jakob Stokholm, Klaus Bønnelykke \\ and Hans Bisgaard * (D)
}

check for updates

Citation: Nørgaard, S.K.; Vissing, N.H.; Chawes, B.L.; Stokholm, J.; Bønnelykke, K.; Bisgaard, H. Cost of Illness in Young Children: A Prospective Birth Cohort Study. Children 2021, 8, 173. https:// doi.org/10.3390/children8030173

Academic Editor: Alan D. Stiles

Received: 28 December 2020

Accepted: 9 February 2021

Published: 24 February 2021

Publisher's Note: MDPI stays neutral with regard to jurisdictional claims in published maps and institutional affiliations.

Copyright: (c) 2021 by the authors. Licensee MDPI, Basel, Switzerland. This article is an open access article distributed under the terms and conditions of the Creative Commons Attribution (CC BY) license (https:// creativecommons.org/licenses/by/ $4.0 /)$.
Copenhagen Prospective Studies on Asthma in Childhood (COPSAC), Herlev and Gentofte Hospital, University of Copenhagen, 2820 Gentofte, Denmark; sarahkristinepedersen@gmail.com (S.K.N.); nadja.hawwa.vissing@regionh.dk (N.H.V.); chawes@copsac.com (B.L.C.); stokholm@copsac.com (J.S.); kb@copsac.com (K.B.)

* Correspondence: bisgaard@copsac.com; Tel.: +45-38677360
Abstract: Childhood illness is extremely common and imposes a considerable economic burden on society. We aimed to quantify the overall economic burden of childhood illness in the first three years of life and the impact of environmental risk factors. The study is based on the prospective, clinical mother-child cohort Copenhagen Prospective Studies on Asthma in Childhood (COPSAC2010) of 700 children with embedded randomized trials of fish-oil and vitamin D supplementations during pregnancy. First, descriptive analyses were performed on the total costs of illness, defined as both the direct costs (hospitalizations, outpatient visits, visit to the practitioner) and the indirect costs (lost earnings) collected from the Danish National Health Registries. Thereafter, linear regression analyses on log-transformed costs were used to investigate environmental determinants of the costs of illness. The median standardized total cost of illness at age $0-3$ years among the 559 children eligible for analyses was EUR 14,061 (IQR 9751-19,662). The exposures associated with reduced costs were fish-oil supplementation during pregnancy (adjusted geometric mean ratio (GMR) 0.89 (0.80; $0.98), p=0.02)$, gestational age in weeks (aGMR $=0.93(0.91 ; 0.96), p<0.0001)$, and birth weight per $100 \mathrm{~g}$ (aGMR $0.98(0.97 ; 0.99), p=0.0003)$, while cesarean delivery was associated with higher costs (aGMR $=1.30(1.15 ; 1.47), p<0.0001)$. In conclusion, common childhood illnesses are associated with significant health-related costs, which can potentially be reduced by targeting perinatal risk factors, including maternal diet during pregnancy, cesarean delivery, preterm birth and low birth weight.

Keywords: cesarean delivery; costs of illness; childhood

\section{Introduction}

Childhood illness is very common in the general population, particularly in the first three years of life [1]. The majority of illnesses are simple infections such as respiratory, gastrointestinal or feverish episodes of short duration. Other common childhood illnesses include allergies, skin problems, eye conditions, neurological issues and gastrointestinal conditions. The majority of these illnesses are mild and easily treated, often without or with very brief healthcare contact, but due to their high frequency, they constitute a sizeable economic burden to society due to healthcare utilization and parents' work absenteeism [1] Nevertheless, knowledge on the economic costs of childhood illness is sparse despite the fact that the percentage of Gross Domestic Product used on healthcare is increasing and puts pressure on the welfare systems of industrialized countries [2,3]). Most studies on the costs of childhood illnesses focus on the costs of a single illness, e.g., asthma [4-6], or a group of related illnesses such as lower respiratory tract infections [7]. So far, no studies have dealt with the total costs of common childhood illnesses, including nonsevere self-limiting infections, which are not easily studied in larger populations, since they often do not require visits to medical facilities, but can be treated at home. 
There are a few known modifiable risk factors that increase childhood illness in general, which can be targeted to reduce costs. Cesarean delivery is one such risk factor, which has increased due to changes in obstetrical practices, medical risk profiles and increasing "maternal request". Children delivered by cesarean section have an increased risk of a range of immune-related diseases such as asthma, inflammatory bowel disease, leukaemia, and immune deficiencies [8], which might be reflected in the overall health-related costs, tracking from birth into early childhood.

We have previously shown in a randomized controlled trial (RCT) that maternal fish-oil supplementation in pregnancy reduces the risk of asthma and lower respiratory tract infections in childhood [8,9]. Likewise, we showed that vitamin D supplementation in pregnancy may also have clinically important protective effects on the same type of illnesses [10], which are some of the most common chronic childhood illnesses [11] and therefore a substantial contributor to health-related costs in childhood. These pregnancy dietary interventions, cesarean section and possibly other modifiable environmental risk factors therefore have the potential for reducing the health-related costs of childhood illness.

The aim of this study was to estimate the overall economic burden on society caused by childhood illness the first three years of life by using data from a prospective, clinical population-based mother-child cohort study. Secondly, to investigate whether a range of early life environmental risk factors, including the effects of dietary supplements with vitamin D and fish-oil in pregnancy are related to the costs of illness in early childhood in order to identify targets to reduce costs of childhood illness.

\section{Materials and Methods}

\subsection{Study Population}

COpenhagen Prospective Study on Asthma in Childhood (COPSAC 2010 ) is a longitudinal, population-based mother-child cohort study of 700 Danish children born from 2009 to 2011. The mothers were included during pregnancy and the children were followed closely from birth with scheduled clinical visits as well as acute visits for any acute airway and/or skin symptoms. The cohort study design and baseline characteristics have previously been thoroughly described [12]. Data validation and quality control followed the guidelines for good clinical practice.

\subsection{Illness}

Child illness was monitored by health interviews with the parents during visits at the COPSAC clinic supported by daily diary cards filled prospectively from birth by parents monitoring the child's symptoms of illness between clinic visits. The diary cards were reviewed with the family by the COPSAC pediatricians at each visit to validate symptom definitions and entries. For the first three years of life the children were seen at age 1 week, 1 month, 3 months, 6 months and six-monthly hereafter. Prior to the health interview sessions, data were retrieved from the regional hospital register and The Danish National Prescription Register $[10,13]$ on hospital admissions, outpatient contacts and prescribed medication to be confirmed by the parents at every visit.

\subsection{Parent Work Absenteeism}

In the diary cards, parents also specifically registered daycare absenteeism due to illness. The number of days home from daycare causing parent absenteeism due to illness were estimated based on this diary registration. Only weekdays (Monday-Friday) were included in the estimation.

\subsection{Estimation of Costs}

The costs of illness were investigated as "direct costs", "observed total costs" and "standardized total costs": "Direct costs" were defined as the direct medical expenditures associated with contact with the healthcare system, including payments for hospital outpatient services, hospital inpatient stays, emergency department visits, physician and 
facility payments. Data were retrieved from the Danish National Health Registers (The Danish National Health Service Register [14] and the Danish National Patient Register [15], which encompass information on all contacts a citizen has with the healthcare system with subsequent fixed reimbursements to the healthcare provider. The total reimbursement related to an episode of illness was used as a proxy for the direct costs of the medical event.

"Direct costs" were grouped according to the type of healthcare service: "physician costs", "hospital admission costs" and "hospital outpatient costs". "Physician costs" include costs related to visits to private practitioners, including general practitioners and specialized doctors. "Hospital costs" include the costs of hospital admissions estimated by the reimbursement received by the hospital after treatment has ended. "Outpatient costs" include the costs of outpatient hospital visits estimated as the reimbursement received by the hospital after each visit. The "indirect costs" include lost earnings due to parent absenteeism when their child is ill. The indirect costs were estimated as both "observed indirect costs", based on the annual household income adjusted for the number of parents in the household, and as "standardized indirect costs" based on a standardized salary [16]. The "total cost" per child was estimated as the sum of all direct and indirect costs of illness during the child's first three years of life with "observed total costs" being based on observed household income and "standardized total costs" being based on a standardized salary. All costs were stated in EUR 2017.

\subsection{Pregnancy Interventions}

Two double-blind RCTs were conducted in the COPSAC 2010 cohort: (1) Mothers were assigned to a daily supplement of either $2.4 \mathrm{~g}$ n-3 LCPUFA (fish-oil) or control (olive oil) [9]. (2) Mothers were assigned to a daily supplement of either high dose vitamin D3 (2800 IU) or standard dose (400 IU) $[9,10]$. Both supplements were given in a $2 \times 2$ factorial design from week 24 of pregnancy to 1 week after birth.

\subsection{Environmental Risk Factors}

Highly detailed risk factor assessment is a key feature of the COPSAC 2010 study, see http:/ / copsac.com/available-data / (accessed 20 February 2020). This includes information on a wide range of environmental and constitutional factors collected prospectively [12]. On the basis of the literature [17-25], 18 environmental risk factors were chosen a priori for suspected relevance for incidence of childhood illness: maternal smoking during 3rd trimester of pregnancy (yes/no); maternal age at birth (years); maternal allergic disease (asthma, eczema or rhinitis); maternal prepregnancy BMI; preeclampsia (yes/no); cesarean delivery (yes/no); sex (male vs. female); prematurity ( $<37$ weeks of gestation) (yes/no); gestational age (GA) (weeks); birth weight (100 g); season of birth (spring, summer, fall or winter); older siblings at birth (yes/no); living with cats at home at birth (yes/no); living with dogs at home at birth (yes/no); duration of solely breastfeeding (months); social circumstances (see Appendix A for definition); day care attendance (age at start in years) and type of day care (nursery vs. private daycare).

\subsection{Statistics}

Descriptive statistics of the costs of child illness and the number of days with parental work absenteeism due to child illness were performed. The incidences of disease during the first three years of life were estimated by ICD-10 group. Differences in baseline characteristics between groups were compared with Chi-squared test for categorical variables and Student's t-test for continuous variables.

The effects of the pregnancy interventions with fish-oil and high-dose vitamin $\mathrm{D}$ on the costs of child illness were investigated with linear regression models on log-transformed costs of illness (standardized total costs, observed total costs, direct costs), estimated as crude Geometric Mean Ratios (GMR). The effects of the interventions on number of days absent from daycare were investigated with Poisson regression models estimated as Odds Ratios (OR). 
Thereafter, linear regression models on the log-transformed costs adjusted for the fish-oil intervention were used to investigate associations between environmental factors and costs of illness for each environmental factor. Poisson models adjusted for the fishoil intervention were used for associations between environmental factors and daycare absenteeism. A multivariate model excluding collinear factors was fitted for all factors, which were significantly associated with more than one type of costs. Additionally, the actual costs were calculated based on the estimates and geometric mean (GM). For parental work absenteeism, the costs were standardized based on average daily salaries in three countries: Denmark, the United Kingdom and the USA.

We performed a subanalysis excluding children of mothers who received active fish-oil supplementation, previously shown to be significantly associated with childhood illness [26], for generalizability to a nontreated population. We also performed subanalyses elaborating the association between cesarean delivery and costs of illness, stratifying by mode of delivery and age in years, and adjusted for GA and birth weight. We performed sensitivity analyses investigating only: (1) children born after GA 37 weeks, (2) children without asthmatic symptoms before age 3, and (3) the costs of hospitalizations. Additionally, a linear regression model was used to investigate the association between log-transformed costs and type of cesarean section (planned vs. acute) in the subpopulation born by cesarean delivery.

A significance level of 0.05 and $95 \%$ confidence intervals were used unless otherwise stated. Missing data were treated as missing observations. All statistics were performed with R (version 3.5.1 (2 July 2018)). All results are stated in EUR 2017.

\section{Results}

\subsection{Baseline Characteristics}

Of the 700 children included in the COPSAC 2010 mother-child cohort, we excluded children who did not complete the first 3 years of the study, children with less than $90 \%$ of the daily diary registrations and children not registered in the National Danish Register, leaving 559 (80\%) eligible children for analysis (Figure S1). The baseline characteristics of the participants are summarized in Table 1 . The children in the study population were less often born by cesarean delivery and had fewer dogs at home at the time of birth compared to the children excluded (Table S1).

Table 1. Baseline characteristics of the study population.

\begin{tabular}{lr}
\hline \multicolumn{2}{c}{ Study Population } \\
\hline Fish-oil supplement, $n$ (\%) & $282(50.5)$ \\
High-dose vitamin D supplement, $n(\%)$ & $230(41.1)$ \\
Maternal smoking, $n(\%)$ & $16(2.9)$ \\
Maternal age (years), mean \pm sd & $32.30 \pm 4.12$ \\
Maternal atopic disease, $n(\%)$ & $312(55.9)$ \\
Maternal prepregnancy BMI, mean \pm sd & $24.56 \pm 4.43$ \\
Preeclampsia, $n(\%)$ & $29(5.2)$ \\
Cesarean delivery, $n(\%)$ & $110(19.7)$ \\
Male, $n(\%)$ & $282(50.4)$ \\
Premature, $n(\%)$ & $21(3.8)$ \\
GA (weeks), mean \pm sd & $39.87 \pm 1.71$ \\
Birth weight $(100 g)$, mean \pm sd & $35.26 \pm 5.52$ \\
Season of birth, $n(\%)$ & \\
$\quad$ Summer & $114(20.4)$ \\
$\quad$ Autumn & $120(21.5)$ \\
$\quad$ Winter & $171(30.6)$ \\
Spring & $154(27.5)$ \\
Older siblings, $n(\%)$ & $313(56.0)$ \\
Cat at birth, $n(\%)$ & $111(19.9)$ \\
Dog at birth, $n(\%)$ & $97(17.4)$ \\
Breastfed (months), mean \pm sd & $3.42 \pm 1.93$ \\
Social circumstances, mean \pm sd & $0.02 \pm 0.95$ \\
Day care (years), mean \pm sd & $0.90 \pm 0.24$ \\
Type of daycare (nursery), $n(\%)$ & $352(66.0)$ \\
\hline
\end{tabular}


Figure 1 shows the burden of child illness experienced during the first three years of life according to the ICD-10 classification [27]. A total of $311(56 \%)$ of the children were hospitalized during the first three years of life, while $231(41 \%)$ of the children were hospitalized after the age of 30 days.



Figure 1. Incidence of disease. The incidence of the eight most common disease by ICD10-group among the 559 participants during the first three years of life.

\subsection{Costs of Illness}

Figure 2 shows the distribution of the different types of costs and Tables S2 and S3 displays the descriptive statistics of the costs and days absent from daycare during the child's first three years of life. The median crude overall costs of childhood illness were EUR 10,932 per child throughout the first three years of life, with a median direct cost of EUR 4225. When indirect costs due to parental work absenteeism were estimated using standardized salaries, the total costs were EUR 13,290. In the subgroup of children ( $n=276)$ whose mothers did not receive fish-oil supplementation the costs were slightly higher: observed total costs, EUR 11,987; direct costs, EUR 4372; and standardized total costs, EUR 14,061, respectively. Excluding children $(n=158)$ whose mothers received high-dose vitamin D supplementation resulted in similar estimates: observed total costs, EUR 11,469; direct costs, EUR 4116; and standardized total costs: EUR 13,553.

The crude median number of days absent from daycare due to illness was 24 days (IQR 15-37). When accounting for time enrolled in daycare, the median number of days was 12 days per year in day care (IQR 7-17). In the subgroup of children whose mothers did not receive fish-oil supplementation the median number of days absent was 26 days (IQR 16-39). Excluding children whose mothers received high-dose vitamin D supplementation resulted in a similar estimate of 26 days (IQR 14-41). 




Figure 2. Distributions of costs. Distributions of costs during the first three years of life.

\subsection{Pregnancy Nutritional Interventions}

Fish-oil supplementation in pregnancy was associated with lower total costs during the first three years of life (standardized total costs: GMR $=0.8995 \% \mathrm{CI}=(0.80 ; 0.98)$, $p=0.021)$ and showed a trend of association with lower direct costs $(\mathrm{GMR}=0.88(0.76 ; 1.02)$, $p=0.09)$ and number of days absent from daycare $(\mathrm{OR}=0.90(0.80 ; 1.01), p=0.07)$. There were no associations between high-dose vitamin D supplementation in pregnancy and costs or number of days absent from daycare ( $p$-values $>0.15)$. The baseline characteristics of the four intervention groups are summarized in Table S1B.

\subsection{Environmental Risk Factors}

Table 2 shows the associations between environmental risk factors and costs and days absent from daycare (adjusted for fish-oil supplementation in pregnancy) along with an estimation of the related costs. Environmental factors significantly associated with standardized total costs, observed total costs and direct costs of illness were cesarean delivery, sex, GA, prematurity, and birth weight. Cesarean delivery was also significantly associated with an increased number of days absent from daycare. Table S3 shows the corresponding costs of parental absenteeism based on average daily salaries in Denmark, the United Kingdom and the USA. Higher age at introduction to daycare was associated with lower total costs and attending a nursery compared to a private daycare was associated with higher costs. The direct costs were not associated with the number of days absent from daycare. Limiting the study population to the children whose mothers did not receive fish-oil supplementation during pregnancy did not alter the results (Table S4).

We performed a multivariate analysis including the variables: cesarean delivery, GA, birth weight, sex, and fish-oil supplementation on the costs of illness (standardized total costs, observed total costs and direct costs). In this model, cesarean delivery remained significant for all types of costs, e.g., standardized total costs: aGMR = $1.24(1.09 ; 1.40)$, $p=0.001$, whereas sex remained significantly associated only with the total costs: standardized total costs: $\mathrm{aGMR}=1.15(1.04 ; 1.27), p=0.006$. Due to the strong collinearity between GA and birth weight $(r=0.65)$, each of these variables were excluded when evaluating the other. Both remained significant for all three types of costs, e.g., aGMR estimates for standardized total cost were $0.94(0.92 ; 0.97)$ and $0.98(0.97 ; 0.99)$ per week GA and per $100 \mathrm{~g}$ birth weight, respectively. There were no significant associations with birth weight when adjusting for GA (data not shown). 



in bold.

\begin{tabular}{|c|c|c|c|c|c|c|c|c|}
\hline \multirow[b]{2}{*}{ Environmental Factor } & \multicolumn{2}{|c|}{ Standardized Total Costs } & \multicolumn{2}{|c|}{ Observed Total Costs } & \multicolumn{2}{|c|}{ Direct Costs } & \multicolumn{2}{|c|}{ Days Home from Daycare } \\
\hline & $\begin{array}{c}\text { aGMR (95\% CI) } \\
(p \text {-Value })\end{array}$ & $\begin{array}{l}\text { Interpretation } \\
\text { (Euro) }\end{array}$ & $\begin{array}{c}\text { aGMR }(95 \% \text { CI }) \\
(p \text {-Value })\end{array}$ & $\begin{array}{l}\text { Interpretation } \\
\text { (Euro) }\end{array}$ & $\begin{array}{c}\text { aGMR (95\% CI) } \\
(p \text {-Value })\end{array}$ & $\begin{array}{l}\text { Interpretation } \\
\text { (Euro) }\end{array}$ & $\begin{array}{c}\text { aOR }(95 \% \mathrm{CI}) \\
(p \text {-Value })\end{array}$ & $\begin{array}{l}\text { Interpretation } \\
\text { (Days) }\end{array}$ \\
\hline $\begin{array}{l}\text { High-dose vitamin D } \\
\text { suppl. }\end{array}$ & $1.05(0.95: 1.17) 0.32$ & $708(-660 ; 2223)$ & $107(0.96 \cdot 119) 020$ & $733(-378 \cdot 1966)$ & $104(0.89 \cdot 1.21) 0.62$ & $158(-439 \cdot 853)$ & م999 $098 \cdot 112) 0$ & $-02(-30 \cdot 30)$ \\
\hline Maternal smoking & $1.19(0.88 ; 1.61) 0.25$ & $2602(-1555 ; 8210)$ & $1.12(0.83 ; 1.53) 0.46$ & $1304(-1819 ; 5557)$ & $1.60(1.02 ; 2.5) 0.039$ & $2450(101 ; 6117)$ & $1.10(0.79 ; 1.57) 0.60$ & $2.05(-5.5 ; 14.8)$ \\
\hline Maternal age & $1.00(0.99 ; 1.02) 0.43$ & $66(-97 ; 231)$ & $1.02(1.01 ; 1.03) 0.004$ & $195(64 ; 329)$ & $1.02(1.00 ; 1.03) 0.08$ & $66(-8 ; 142)$ & $1.00(0.98 ; 1.01) 0.78$ & $-0.1(-0.4 ; 0.3)$ \\
\hline $\begin{array}{l}\text { Maternal atopic disease } \\
\text { Maternal pre pregnancy }\end{array}$ & $1.10(1.00 ; 1.22) 0.06$ & $1390(-31 ; 2962)$ & $1.07(0.97 ; 1.19) 0.19$ & $758(-347 ; 1984)$ & $1.22(1.05 ; 1.42) 0.009$ & $899(206 ; 1703)$ & $1.05(0.93 ; 1.18) 0.42$ & $1.03(-1.7 ; 4.6)$ \\
\hline BMI & $1.00(0.99 ; 1.01) 0.60$ & $41(-111 ; 196)$ & $1.00(0.99 ; 1.01) 0.85$ & $11(-110 ; 135)$ & $1.01(1.00 ; 1.03) 0.13$ & $53(-16 ; 124)$ & $1.00(0.99 ; 1.01) 0.87$ & $0.0(-0.4 ; 0.3)$ \\
\hline Preeclampsia & $\begin{array}{l}1.29(1.03 ; 1.61) 0.03 \\
1.30(1.15 ; 1.47)\end{array}$ & $3841(360 ; 8199)$ & $\begin{array}{l}1.25(0.99 ; 1.58) 0.06 \\
\mathbf{1 . 3 3}(\mathbf{1 . 1 7} ; \mathbf{1 . 5 1})\end{array}$ & $2618(-85 ; 6025)$ & $\begin{array}{l}1.12(0.80 ; 1.57) 0.51 \\
\mathbf{1 . 4 5}(\mathbf{1 . 2 0} ; \mathbf{1 . 7 4 )}\end{array}$ & $484(-821 ; 2310)$ & $1.29(1.01 ; 1.68) 0.05$ & $7.05(0.1 ; 17.6)$ \\
\hline Cesarean delivery & $<0.0001$ & $4061(2021 ; 6372)$ & $\begin{array}{l}<0.0001 \\
1.18(1.06 ; 1.30)\end{array}$ & $3424(1764 ; 5310)$ & $\begin{array}{l}0.0001 \\
1.17(1.01 ; 1.36)\end{array}$ & $1822(824 ; 3022)$ & $1.17(1.02 ; 1.35) 0.029$ & $4.05(0.5 ; 9.2)$ \\
\hline Male & $\begin{array}{l}1.16(1.05 ; 1.28) 0.004 \\
0.93(0.91 ; 0.96)\end{array}$ & $2105(631 ; 3733)$ & $\begin{array}{l}0.0019 \\
0.92(0.90 ; 0.95)\end{array}$ & $1852(655 ; 3178)$ & $\begin{array}{l}0.0371 \\
0.84(0.81 ; 0.88)\end{array}$ & $703(40 ; 1471)$ & $1.03(0.92 ; 1.16) 0.58$ & $0.09(-2.0 ; 4.1)$ \\
\hline GA (weeks) & $\begin{array}{l}<0.0001 \\
2.00(1.55 ; 2.59)\end{array}$ & $-901(-1259 ;-534)$ & $\begin{array}{l}<0.0001 \\
2.21(1.70 ; 2.87)\end{array}$ & $-789(-1071 ;-499)$ & $\begin{array}{l}<0.0001 \\
4.08(2.81 ; 5.94)\end{array}$ & $-645(-785 ;-499)$ & $1.03(0.99 ; 1.06) 0.14$ & $0.07(-0.2 ; 1.6)$ \\
\hline Premature & $\begin{array}{l}<0.0001 \\
0.98(0.97 ; 0.99)\end{array}$ & $13492(7392 ; 21378)$ & $\begin{array}{l}<0.0001 \\
0.98(0.97 ; 0.99)\end{array}$ & $12606(7278 ; 19536)$ & $\begin{array}{l}<0.0001 \\
0.96(0.95 ; 0.98)\end{array}$ & $12600(7391 ; 20175)$ & $0.86(0.64 ; 1.17) 0.31$ & $-3.7(-9.4 ; 4.5)$ \\
\hline $\begin{array}{l}\text { Birth weight }(100 \mathrm{~g}) \\
\text { Season of birth (ref: } \\
\text { summer) }\end{array}$ & 0.0003 & $-225(-343 ;-105)$ & 0.0002 & $-186(-281 ;-90)$ & $<0.0001$ & $-144(-196 ;-92)$ & $1.00(0.99 ; 1.01) 0.69$ & $-0.1(-0.3 ; 0.2)$ \\
\hline Winter & $0.93(0.81 ; 1.08) 0.35$ & $-895(-2566 ; 1033)$ & $0.93(0.81 ; 1.08) 0.36$ & $-692(-2025 ; 852)$ & $0.95(0.77 ; 1.18) 0.66$ & $-192(-939 ; 734)$ & $0.94(0.80 ; 1.11) 0.50$ & $-1.40(-5.2 ; 2.9)$ \\
\hline Spring & $0.98(0.85 ; 1.14) 0.81$ & $-243(-2036 ; 1831)$ & $\begin{array}{l}0.99(0.85 ; 1.14) 0.84 \\
\mathbf{1 . 1 1}(\mathbf{1 . 0 0} ; \mathbf{1 . 2 3})\end{array}$ & $-156(-1591 ; 1511)$ & $0.98(0.78 ; 1.21) 0.82$ & $101(-881 ; 869)$ & $1.00(0.85 ; 1.18) 0.99$ & $0.0(-4.0 ; 4.8)$ \\
\hline Older siblings at birth & $1.08(0.97 ; 1.19) 0.16$ & $1015(-372 ; 2549)$ & 0.0496 & $1146(4 ; 2412)$ & $1.06(0.92 ; 1.24) 0.42$ & $262(-345 ; 967)$ & $1.22(1.04 ; 1.44) 0.015$ & $1.6(-1.4 ; 5.0)$ \\
\hline Cat at birth & $0.95(0.84 ; 1.08) 0.45$ & $-639(-2148 ; 1073)$ & $0.91(0.80 ; 1.03) 0.14$ & $-969(-2115 ; 336)$ & $0.95(0.79 ; 1.15) 0.63$ & $-184(-849 ; 618)$ & $1.02(0.83 ; 1.26) 0.83$ & $0.40(-3.1 ; 4.5)$ \\
\hline Dog at birth & $0.95(0.83 ; 1.08) 0.43$ & $-701(-2284 ; 1107)$ & $0.92(0.80 ; 1.05) 0.21$ & $-879(-2100 ; 521)$ & $1.21(0.99 ; 1.47) 0.06$ & $843(-39 ; 1917)$ & $0.82(0.66 ; 1.03) 0.08$ & $-4.2(-7.2 ;-0.5)$ \\
\hline Social circumstances & $0.99(0.94 ; 1.05) 0.85$ & $-68(-753 ; 654)$ & NA & NA & $0.97(0.90 ; 1.05) 0.43$ & $-127(-425 ; 196)$ & $1.00(0.92 ; 1.09) 0.97$ & $-1.0(-1.6 ; 1.5)$ \\
\hline Solely breastfed (mths) & $\begin{array}{l}1.00(0.98 ; 1.03) 0.89 \\
\mathbf{0 . 9 7}(\mathbf{0 . 9 5} \mathbf{0 . 9 9 )}\end{array}$ & $25(-320 ; 379)$ & $1.00(0.98 ; 1.03) 0.75$ & $45(-231 ; 329)$ & $0.97(0.93 ; 1.01) 0.10$ & $-131(-280 ; 25)$ & $1.00(0.96 ; 1.04) 0.97$ & $0.3(-0.5 ; 1.0)$ \\
\hline $\begin{array}{l}\text { Introduction to daycar } \\
\text { (mht) } \\
\text { Type of daycare }\end{array}$ & $\begin{array}{l}0.0009 \\
1.23(1.11 ; 1.37)\end{array}$ & $-394(-621 ;-164)$ & $\begin{array}{l}0.97(0.96 ; 0.99) 0.004 \\
1.27(1.13 ; 1.41)\end{array}$ & $-274(-456 ;-89)$ & $1.00(0.97 ; 1.02) 0.90$ & $-7(-113 ; 102)$ & $0.96(0.93 ; 1.00) 0.009$ & $-1.3(-1.9 ;-0.7)$ \\
\hline (nursery) & 0.0001 & $3101(1440 ; 4948)$ & $<0.0001$ & $2773(1409 ; 4293)$ & $0.94(0.80 ; 1.11) 0.48$ & $-232(-809 ; 446)$ & $1.33(1.12 ; 1.58) 0.001$ & $9.0(5.1 ; 13.3)$ \\
\hline
\end{tabular}




\subsection{Cesarean Delivery}

A total of $110(20 \%)$ children were born by cesarean delivery, of which $49(45 \%)$ were planned procedures. The association between cesarean delivery and the costs of illness remained significant after adjustment for GA, birth weight and fish-oil supplementation: standardized total costs: aGMR $=1.24(1.10 ; 1.41), p<0.001$; and direct costs: $\mathrm{aGMR}=1.25,(1.04 ; 1.50), p=0.017$. Excluding costs of hospitalizations (standardized total costs: aGMR $=1.17(1.04 ; 1.33), p=0.011$; and direct costs: aGMR $=1.17,(1.01 ; 1.35)$, $p=0.037$ ) or excluding children born before GA 37 weeks from the analyses did not change the associations (standardized total costs: $\mathrm{aGMR}=1.22(1.07 ; 1.39), p=0.003$; and direct costs: aGMR $=1.27(1.05 ; 1.53), p=0.013)$. Excluding children with asthmatic symptoms in the first three years of life also did not change the associations: standardized total costs: $\mathrm{aGMR}=1.28(1.12 ; 1.47), p<0.001$; and direct costs: aGMR $=1.37(1.12 ; 1.69), p=0.002$. Stratifying the analyses by the first, second or third year of life did not alter the results (Figure 3). There were no differences in cost with respect to whether the cesarean delivery was planned or acute: standardized total costs: $\mathrm{aGMR}=1.07(0.84 ; 1.37), p=0.57$; and direct costs: $\mathrm{aGMR}=1.02(0.69 ; 1.52), p=0.92)$. Figure $\mathrm{S} 2$ shows the incidences of diagnoses from Figure 1 stratified by delivery mode and Figure S3 shows the distribution of costs from Figure 2 stratified by delivery mode.
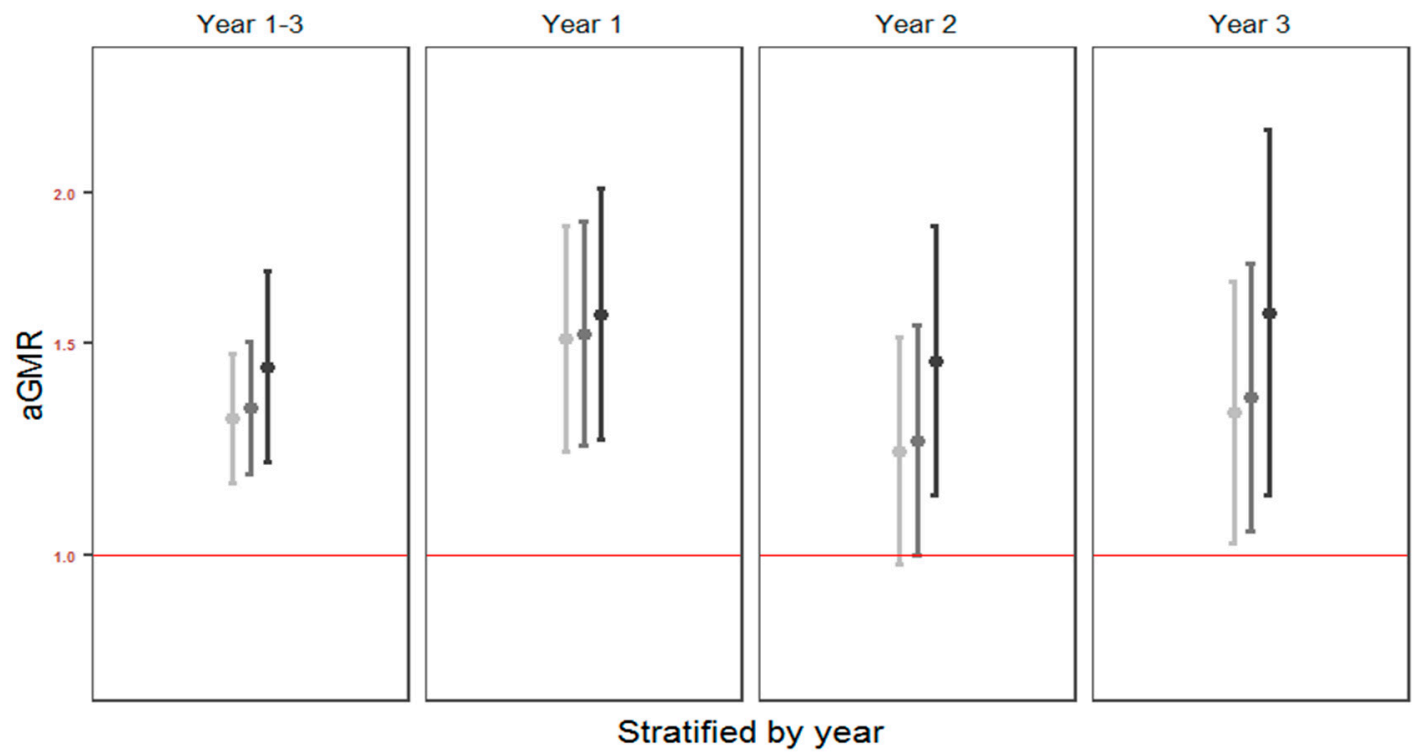

Stratified by year

Figure 3. Costs by mode of delivery. The associations between cesarean delivery and costs adjusted for fish-oil supplementation during pregnancy. Adjusted geometric mean ratios of the associations between cesarean delivery and standardized total costs (light grey), observed total costs (middle grey) and direct costs (dark grey) with corresponding 95\% confidence intervals stratified by year of life.

\section{Discussion}

\subsection{Primary Findings}

We found that the median observed total cost of illness in the first three years of life among 559 unselected, population-based Danish children was EUR 10,932 and the median number of days absent from daycare was 24 . Birth by cesarean delivery was associated with $30-45 \%$ higher costs and a $17 \%$ higher number of days absent from daycare due to illness. Cesarean delivery was significantly associated with all measures of health costs, both direct and indirect, and the association persisted throughout all three study years. Male sex, low GA and low birth weight were also associated with higher costs of child illness, whereas fish-oil supplementation during pregnancy was associated with $12 \%$ lower health-related costs in the offspring during the first three years of life. These findings may be useful for developing strategies to avoid or reduce costs of childhood illness. 


\subsection{Strengths and Limitations}

A major strength of the study is the longitudinal, prospective clinical surveillance of a mother-child cohort at the COPSAC clinical research unit. The study is a single-center study with assessments by experienced study-physicians, examining the cohort children and obtaining the clinical history based on standard operating procedures supported by daily diary cards. We only included children with at least $90 \%$ of days actively observed. This method assures a high sensitivity, consistency in procedures, uniform case definitions, secure data capture methods, and reduced risk of misclassification.

The data source for assessing costs is unique due to the possibility of linking data from national registries to each cohort participant via the Central Person Registration number, which is assigned to all persons with a permanent residence in Denmark. The Danish National Registries contain information on all the population's contacts with the Danish healthcare system due to the reimbursement system, where the providers are not reimbursed without a correct registration, which strengthens the credibility of the Danish National Registries. The private sector in Denmark is neglectable, particularly regarding children, with no inpatient facilities, thus equalizing the gap in healthcare differences within the population. Still, the costs in the register are average numbers and not calculated for individual hospitalizations; however, we do not expect the numbers to be systematically over- or underestimated.

It is a strength that we were able to consider the burden of parental absenteeism as a part of costs related to childhood illness, which are rarely included in cost analyses. We acknowledge that there might be additional intangible costs, such as reduced quality of life, and secondary transmissions of illness from child to parent, which we were not able to include, and the true cost of childhood illness is probably still underestimated.

The generalizability of our findings is limited by an unintended recruitment bias towards families with atopic illness, conferring a higher risk of those illnesses in their children. In fact, half of the parents were diagnosed with an atopic illness, which is higher than expected in the population [28]. Still, considering the high prevalence of asthma among adults of reproductive age in industrialized countries [29], our results are relevant to a substantial proportion of the population. We observed a high rate of hospital admissions among children $(56 \%)$, but this is in line with recent studies in a similar Danish population [30]. The generalizability can also be questioned by the relatively good health of our families with low rates of risk factors for poor health such as prematurity, parental smoking, overweight etc. It is therefore possible that we underestimate the level of healthcare utilization. However, families with better health risk profiles could potentially have other doctor seeking behaviors and costs could be higher in this subgroup.

The level of household income in our study is marginally higher as compared to the general population [12], which could lead to an overestimation of the indirect costs of illness. With that in mind, we also estimated the standardized total costs of illness using a fixed daily salary based on average incomes in both Denmark, UK and USA.

Finally, the association between fish-oil supplementation during pregnancy and total costs of child illness is specifically strengthened by the RCT study design.

\subsection{Interpretation}

We found that fish-oil supplementation from pregnancy week 24 to one week postpartum reduced the costs of illness in early childhood by $12 \%$. This suggests fish-oil supplementation for pregnant women as a simple way to reduce the health-related costs of early childhood illnesses. The estimated health expenditure benefit from fish-oil supplementation of $12 \%$ of the median observed total cost corresponds to EUR 1400 per child. When we take into account that 61,397 children were born in Denmark in 2017, this reduction of cost amounts to EUR 85,400,000 yearly. Even though full compliance with such future supplementation strategy cannot be expected from the entire population of pregnant women, this would still have the capacity to significantly reduce the health-related costs of childhood illness worldwide. 
Children born by cesarean delivery had $30-45 \%$ higher costs of illness than children born by vaginal delivery without any differences between planned or acute cesarean delivery. The association between cesarean delivery and increased costs was not only caused by a higher risk of hospitalization perinatally since both total and direct costs of illness without the costs of hospitalizations were significantly associated to the mode of delivery, which persisted during all three years. The association between cesarean delivery and the costs of illness was not mediated by an increased number of infants born prematurely with subsequent increased morbidity, since the associations were still significant when they were adjusted for GA and even when we excluded children born before GA 37 weeks.

Cesarean delivery is a known risk factor for childhood asthma (8), and it is therefore plausible that an increased risk of asthma was driving the association between mode of delivery of costs of illness. Other studies have also shown that cesarean delivery is associated with a higher burden of respiratory illness in childhood [31,32], which fit well with our results of higher costs. However, the association remained significant when excluding children experiencing asthma-like symptoms at age $0-3$ years. The incidence rate of cesarean sections is increasing in Denmark, as in many other countries [33], but there are considerable regional differences [34] depending on local obstetrical practices and maternal preferences. The World Health Organization (WHO) has estimated that caesarean section rates above $10 \%$ are not correlated with reduced maternal and newborn mortality rates at population level [35], suggesting that it might be possible to lower the rates without health consequences. Our findings stress a potential adverse health effect to the child as well as to society through increasing cost of illness when choosing a cesarean delivery. This is particularly an issue when the procedure is not absolutely medically indicated. Such knowledge on the long-term effects of the procedure may support the clinician, the families and the general healthcare providers in their decision making.

It should be noted that our study identifies an association between cesarean delivery and future health costs with no speculations on the exact mechanisms. Our findings could reflect inherent aspects of susceptibility to illness that also increase the risk of cesarean delivery, and that children born by cesarean delivery constitute a preselected group of more vulnerable children. Future clinical studies can hopefully elucidate these associations.

The fact that low birth weight and premature birth are also associated with healthcare costs throughout early childhood, independently of delivery mode, is consistent with previous studies demonstrating that preterm infants have a significantly higher financial burden throughout their childhood [36,37]. The remarkable effect of prenatal fish-oil supplementation points towards the pivotal importance of the pregnancy and neonatal period, and highlights the importance of optimizing prenatal care, even in high-income settings.

This study provides an overview of the costs of illness in Danish children in general, adding to the current knowledge on the economic burden of childhood illness in affluent countries. The issue about parental absenteeism is regularly a part of the public debate on work-life balance, affecting not only the children and their parents but also the employers, and means by which to alleviate this burden are highly relevant.

\section{Conclusions}

Common childhood illnesses are associated with significant health-related costs to society. These costs can potentially be reduced by targeting the pregnancy and perinatal period, including supplementing maternal diet with fish-oil, reducing the rate of cesarean delivery by maternal request, and by preventing preterm birth and low birth weight.

Supplementary Materials: The following are available online at https:/ /www.mdpi.com/2227-906 7/8/3/173/s1: Figure S1: Flow chart; Figure S2: Incidence of disease per 100 children by mode of delivery; Figure S3: Distributions of costs by mode of delivery; Table S1: Drop-out analysis; Table S2: Description of costs; Table S3: Approximated costs of parental absenteeism in different countries; Table S4: Associations between environmental factors and costs in placebo strata; Table S5: Baseline table of original information used to derive the measure of social circumstances. 
Author Contributions: Conceptualization, all authors; methodology, all authors; software, S.K.N.; validation, all authors; formal analysis, S.K.N.; investigation, all authors; resources, H.B.; data curation, S.K.N., N.H.V.; writing—original draft preparation, S.K.N.; writing-review and editing, all authors.; visualization, S.K.N., N.H.V., B.L.C., K.B.; supervision, N.H.V., B.L.C., J.S., K.B., H.B.; project administration, H.B.; funding acquisition, H.B. All authors have read and agreed to the published version of the manuscript.

Funding: There was no specific funding for this study. The Lundbeck Foundation (Grant no R16A1694); The Ministry of Health (Grant no 903516); Danish Council for Strategic Research (Grant no 0603-00280B) and The Capital Region Research Foundation have provided core support to the COPSAC research center.

Institutional Review Board Statement: The study was conducted in accordance with the guiding principles of the Declaration of Helsinki and was approved by the Local Ethics Committee (H-B-2008093, and the Danish Data Protection Agency (2015-41-3696).

Informed Consent Statement: Both parents gave oral and written informed consent before study enrolment.

Data Availability Statement: All materials, computer code and protocols will be made available to readers. However, the data included in the study are classified as sensitive, personally identifiable data. Participant-level personally identifiable data are protected under the Danish Data Protection Act and European Regulation 2016/679 of the European Parliament and of the Council (GDPR) that prohibit distribution even in pseudoanonymized form, and these data therefore cannot be made publicly available, but can potentially be made available under a data transfer agreement as a collaboration effort.

Acknowledgments: We express our deepest gratitude to the children and families of the COPSAC 2010 cohort study for all their support and commitment. We acknowledge and appreciate the unique efforts of the COPSAC research team.

Conflicts of Interest: The authors declare no conflict of interest. The funders had no role in the design of the study; in the collection, analyses, or interpretation of data; in the writing of the manuscript, or in the decision to publish the results.

\section{Appendix A}

Social circumstances: The variable "social circumstances" is defined as the first component of a principal component analysis (PCA) based on household income, maternal age and maternal level of education when the child was 2 years of age (explaining $55 \%$ of the variance) with a mean value of zero and standard deviation of one. The original variables were distributed as in Table S5. The variable "social circumstances" is positively correlated to higher household income $(\mathrm{r}=0.80, p<0.001)$, to higher maternal level of education $(\mathrm{r}=0.74, p<0.001)$ and to higher maternal age $(\mathrm{r}=0.68, p<0.001)$.

\section{References}

1. Vissing, N.H.; Chawes, B.L.; Rasmussen, M.A.; Bisgaard, H. Epidemiology and Risk Factors of Infection in Early Childhood. Pediatrics 2018, 141. [CrossRef] [PubMed]

2. Musgrove, P.; Zeramdini, R.; Carrin, G. Basic patterns in national health expenditure. Bull. World Health Organ. 2002, 80, 134-142.

3. Danish Regions. Available online: https://www.regioner.dk/media/2209/2015-pres-paa-sundhedsvaesenet.pdf (accessed on 25 December 2020).

4. Barnes, P.J.; Jonsson, B.; Klim, J.B. The costs of asthma. Eur. Respir. J. 1996, 9, 636-642. [CrossRef] [PubMed]

5. Lozano, P.; Sullivan, S.D.; Smith, D.H.; Weiss, K.B. The economic burden of asthma in US children: Estimates from the National Medical Expenditure Survey. J. Allergy Clin. Immunol. 1999, 104, 957-963. [CrossRef]

6. Ungar, W.J.; Coyte, P.C.; Pharmacy Medication Monitoring Program Advisory Board. Prospective study of the patient-level cost of asthma care in children. Pediatr. Pulmonol. 2001, 32, 101-108. [CrossRef] [PubMed]

7. Lambert, S.B.; Allen, K.M.; Carter, R.C.; Nolan, T.M. The cost of community-managed viral respiratory illnesses in a cohort of healthy preschool-aged children. Respir. Res. 2008, 9, 11. [CrossRef]

8. Sevelsted, A.; Stokholm, J.; Bønnelykke, K.; Bisgaard, H. Cesarean section and chronic immune disorders. Pediatrics 2015, 135, e92-e98. [CrossRef]

9. Bisgaard, H.; Bønnelykke, K. Fish Oil in Pregnancy and Asthma in Offspring. N. Engl. J. Med. 2017, 376, 1191-1192. 
10. Chawes, B.L.; Bønnelykke, K.; Stokholm, J.; Vissing, N.H.; Bjarnadóttir, E.; Schoos, A.M.; Wolsk, H.M.; Pedersen, T.M.; Vinding, R.K.; Thorsteinsdóttir, S.; et al. Effect of Vitamin D3 Supplementation During Pregnancy on Risk of Persistent Wheeze in the Offspring: A Randomized Clinical Trial. JAMA 2016, 315, 353-361. [CrossRef]

11. Eder, W.; Ege, M.J.; von Mutius, E. The asthma epidemic. N. Engl. J. Med. 2006, 355, 2226-2235. [CrossRef] [PubMed]

12. Bisgaard, H.; Vissing, N.H.; Carson, C.G.; Bischoff, A.L.; Følsgaard, N.V.; Kreiner-Møller, E.; Chawes, B.L.; Stokholm, J.; Pedersen, L.; Bjarnadóttir, E.; et al. Deep phenotyping of the unselected COPSAC2010 birth cohort study. Clin. Exp. Allergy 2013, 43, 1384-1394. [CrossRef]

13. Kildemoes, H.W.; Sørensen, H.T.; Hallas, J. The Danish National Prescription Registry. Scand. J. Public Health $2011,39,38-41$. [CrossRef] [PubMed]

14. Andersen, J.S.; Olivarius ND, F.; Krasnik, A. The Danish National Health Service Register. Scand. J. Public Health 2011, 39, 34-37. [CrossRef]

15. Lynge, E.; Sandegaard, J.L.; Rebolj, M. The Danish National Patient Register. Scand. J. Public Health 2011, $39,30-33$. [CrossRef] [PubMed]

16. (No title). Available online: https://www.statistikbanken.dk/statbank5a/selectvarval/saveselections.asp (accessed on 23 October 2019).

17. Wald, E.R.; Guerra, N.; Byers, C. Frequency and severity of infections in day care: Three-year follow-up. J. Pediatr. 1991, 118, 509-514. [CrossRef]

18. Caudri, D.; Wijga, A.; Scholtens, S.; Kerkhof, M.; Gerritsen, J.; Ruskamp, J.; Brunekreef, B.; Smit, H.A.; de Jongste, J.C. Early daycare is associated with an increase in airway symptoms in early childhood but is no protection against asthma or atopy at 8 years. Am. J. Respir. Crit. Care Med. 2009, 180, 491-498. [CrossRef] [PubMed]

19. Nafstad, P.; Hagen, J.A.; Oie, L.; Magnus, P.; Jaakkola, J.J. Day care centers and respiratory health. Pediatrics 1999, 103, 753-758. [CrossRef]

20. Nafstad, P.; Jaakkola, J.J.; Hagen, J.A.; Botten, G.; Kongerud, J. Breastfeeding, maternal smoking and lower respiratory tract infections. Eur. Respir. J. 1996, 9, 2623-2629. [CrossRef]

21. Zutavern, A.; Rzehak, P.; Brockow, I.; Schaaf, B.; Bollrath, C.; von Berg, A.; Link, E.; Kraemer, U.; Borte, M.; Herbarth, O.; et al. Day care in relation to respiratory-tract and gastrointestinal infections in a German birth cohort study. Acta Paediatr. 2007, 96, 1494-1499. [CrossRef] [PubMed]

22. Cushing, A.H.; Samet, J.M.; Lambert, W.E.; Skipper, B.J.; Hunt, W.C.; Young, S.A.; McLaren, L.C. Breastfeeding reduces risk of respiratory illness in infants. Am. J. Epidemiol. 1998, 147, 863-870. [CrossRef] [PubMed]

23. Watkins, C.J.; Leeder, S.R.; Corkhill, R.T. The relationship between breast and bottle feeding and respiratory illness in the first year of life. J. Epidemiol. Community Health 1979, 33, 180-182. [CrossRef]

24. Jones, L.L.; Hashim, A.; McKeever, T.; Cook, D.G.; Britton, J.; Leonardi-Bee, J. Parental and household smoking and the increased risk of bronchitis, bronchiolitis and other lower respiratory infections in infancy: Systematic review and meta-analysis. Respir. Res. 2011, 12, 5. [CrossRef]

25. Bergroth, E.; Remes, S.; Pekkanen, J.; Kauppila, T.; Büchele, G.; Keski-Nisula, L. Respiratory tract illnesses during the first year of life: Effect of dog and cat contacts. Pediatrics 2012, 130, 211-220. [CrossRef] [PubMed]

26. Bisgaard, H.; Stokholm, J.; Chawes, B.L.; Vissing, N.H.; Bjarnadóttir, E.; Schoos, A.M.; Wolsk, H.M.; Pedersen, T.M.; Vinding, R.K.; Thorsteinsdóttir, S.; et al. Fish Oil-Derived Fatty Acids in Pregnancy and Wheeze and Asthma in Offspring. N. Engl. J. Med. 2016, 375, 2530-2539. [CrossRef]

27. World Health Organization. The International Statistical Classification of Diseases and Related Health Problems; WHO: Geneva, Switzerland, 2009.

28. Svanes, C.; Jarvis, D.; Chinn, S.; Burney, P. Childhood environment and adult atopy: Results from the European Community Respiratory Health Survey. J. Allergy Clin. Immunol. 1999, 103, 415-420. [CrossRef]

29. Backman, H.; Räisänen, P.; Hedman, L.; Stridsman, C.; Andersson, M.; Lindberg, A.; Lundbäck, B.; Rönmark, E. Increased prevalence of allergic asthma from 1996 to 2006 and further to 2016-results from three population surveys. Clin. Exp. Allergy 2017, 47, 1426-1435. [CrossRef] [PubMed]

30. Stensballe, L.G.; Sørup, S.; Aaby, P.; Benn, C.S.; Greisen, G.; Jeppesen, D.L.; Birk, N.M.; Kjærgaard, J.; Nissen, T.N.; Pihl, G.T.; et al. BCG vaccination at birth and early childhood hospitalisation: A randomised clinical multicentre trial. Arch. Dis. Child. 2017, 102, 224-231. [CrossRef]

31. Merenstein, D.J.; Gatti, M.E.; Mays, D.M. The association of mode of delivery and common childhood illnesses. Clin. Pediatr. 2011, 50, 1024-1030. [CrossRef] [PubMed]

32. Baumfeld, Y.; Walfisch, A.; Wainstock, T.; Segal, I.; Sergienko, R.; Landau, D.; Sheiner, E. Elective cesarean delivery at term and the long-term risk for respiratory morbidity of the offspring. Eur. J. Pediatr. 2018, 177, 1653-1659. [CrossRef] [PubMed]

33. Betrán, A.P.; Ye, J.; Moller, A.B.; Zhang, J.; Gülmezoglu, A.M.; Torloni, M.R. The Increasing Trend in Caesarean Section Rates: Global, Regional and National Estimates: 1990-2014. PLoS ONE 2016, 11, e0148343. [CrossRef] [PubMed]

34. Boatin, A.A.; Schlotheuber, A.; Betran, A.P.; Moller, A.B.; Barros, A.J.D.; Boerma, T.; Torloni, M.R.; Victora, C.G.; Hosseinpoor, A.R. Within country inequalities in caesarean section rates: Observational study of 72 low and middle income countries. BMJ 2018, 360, k55. [CrossRef] [PubMed] 
35. World Health Organization, Statement on Caesarean Section Rates. Available online: https://apps.who.int/iris/bitstream/ handle/10665/161442/WHO_RHR_15.02_eng.pdf;jsessionid=19EBBAB2A1E190C16B278564F1B81362?sequence=1 (accessed on 25 December 2020).

36. Khan, K.A.; Petrou, S.; Dritsaki, M.; Johnson, S.J.; Manktelow, B.; Draper, E.S.; Smith, L.K.; Seaton, S.E.; Marlow, N.; Dorling, J.; et al. Economic Costs Associated with Moderate and Late Preterm Birth: A Prospective Population-Based Study. BJOG Int. J. Obstet. Gynaecol. 2015, 122, 1495-1505. [CrossRef]

37. Frey, H.A.; Klebanoff, M.A. The Epidemiology, Etiology, and Costs of Preterm Birth. Semin. Fetal. Neonatal Med. 2016, 21, 68-73. [CrossRef] [PubMed] 